\title{
Workshop on Adverse Drug Reaction Reporting, Pharmacovigilance and Its Implementation in Cancer Hospital in Nepal: An Event Report
}

This article was published in the following Dove Press journal:

Advances in Medical Education and Practice

\author{
Sunil Shrestha $\mathbb{D}^{\prime}$ \\ Ranish Shrestha $\mathbb{D D}^{2}$ \\ Afroz Abidi $\mathbb{I D}^{3}$ \\ Amit Upadhyay ${ }^{4}$ \\ Tara Khanal' \\ Baburam Adhikari ${ }^{1}$ \\ Bijesh Raj Ghimire ${ }^{5}$ \\ 'Department of Pharmacy, Nepal Cancer \\ Hospital and Research Center, Lalitpur, \\ Nepal; ${ }^{2}$ Infection Prevention and Control \\ Unit, Nepal Cancer Hospital and \\ Research Center, Lalitpur, Nepal; \\ ${ }^{3}$ Department of Pharmacology, Era's \\ Lucknow Medical College, Lucknow, UP, \\ India; ${ }^{4}$ Hematology and Hemato \\ Oncology, PSRI Hospital, New Delhi \\ I I00I7, India; ${ }^{5}$ Department of Medical \\ Oncology, Nepal Cancer Hospital and \\ Research Center, Lalitpur, Nepal
}

\begin{abstract}
Adverse drug reactions are crucial events related to drug usage that ought to be reported and the effects of which can be minimized by careful and vigilant use of drugs. Pharmacovigilance refers to the systematic practice of reporting, assessing and preventing such events. Although such practice is vital in any healthcare system, its actual implementation has been found to be very limited in a country like Nepal. With the aim of disseminating information about such events and the role of healthcare professionals in pharmacovigilance, a one-day workshop was organized with international and national speakers on this subject at Nepal Cancer Hospital and Research Center, Lalitpur, Nepal, which also has a regional pharmacovigilance center. The workshop included lectures and hands-on training and had an audience from diverse fields of healthcare such as pharmacy, medical, surgical and radiation oncology, pathology and nursing staff. The feedback from the participants revealed that practical demonstration and hands-on training with extensive topic coverage were the best feature of the workshop, while less interaction during the lectures was a source of dissatisfaction with a recommendation to conduct more events focused on similar topics in the future.
\end{abstract}

Keywords: adverse drug reaction, ADR reporting, Nepal, pharmacovigilance, workshop

\section{Introduction}

Adverse drug reactions (ADRs) have been defined by the World Health Organization (WHO) as:

"a response to a drug that is noxious and unintended and occurs at doses normally used in man for the prophylaxis, diagnosis or therapy of disease, or for modification of physiological function". ${ }^{1}$

According to WHO, Pharmacovigilance (PV) is defined as "the science and activities related to the detection, assessment, understanding and prevention of adverse drug effects or any other possible drug-related problems". ${ }^{2}$

Despite being crucial, the system of pharmacovigilance and voluntary reporting of ADRs has not been fully established in Nepal, with high under-reporting of such events. ${ }^{4}$ Educational interventions have been widely shown to be effective at improving the rate of ADRs reporting among healthcare workers. ${ }^{5-7}$ Conducting workshops as an educational intervention has been shown to increase ADR reporting among physicians. ${ }^{8}$

With this background, a one-day workshop on pharmacovigilance was organized with international and national speakers with the aim to improve the present
Correspondence: Sunil Shrestha Department of Pharmacy, Nepal Cancer Hospital and Research Center, Harisiddhi, Lalitpur, Nepal

Tel +977-985I220488

Email sunilcresta@gmail.com 
knowledge on ADRs and PV among healthcare professionals and to strengthen the trend of reporting ADRs to regional pharmacovigilance center attached to the cancer hospital.

The first objective of this paper was to provide information on the various sessions covered in this workshop, the first of its kind in a cancer care setting in Nepal, which could be useful for future events of similar nature. The primary objective of this paper was to study the immediate feedback of attendees following the workshop to describe their perspective on the most impressive features of the workshop, dissatisfactions and recommendations, which would also be helpful in conducting similar educational events regarding pharmacovigilance and ADRs in the future.

\section{Methods}

On the 7th of July 2019, Nepal Cancer Hospital and Research Center (NCHRC), a tertiary cancer care hospital located at Province No.3, Nepal conducted a workshop on Adverse Drug Reaction reporting, Pharmacovigilance and its implementation in a cancer hospital. The main objectives of this workshop were:

1. To elucidate the concepts of ADR and PV,

2. To highlight the significance of $P V$ and ADR reporting,

3. To describe the system and method of ADR reporting,

4. To describe the activities and updates of the regional $\mathrm{PV}$ center at NCHRC,

5. To elaborate implementation of PV activities at NCHRC, and

6. To introduce the concepts of alternative and complementary medicine in relation to cancer therapy.

An internal email was circulated within the hospital as an invitation to attend the workshop, while information about the workshop was also disseminated on the social media page of the hospital to gain attendees beyond the hospital. The participants were from various backgrounds of the healthcare profession including pharmacists, nurses, doctors and other allied health professionals. Participants were primarily from Nepal Cancer Hospital and Research Center, and also from other hospitals within Kathmandu valley, Nepal. Immediately after the workshop, a feedback form was given to the participants. The form elicited data related to demographics, work experience and educational background, followed by 3 open-ended questions, viz. "Best feature of the workshop", "Dissatisfaction regarding the workshop" and "Recommendations for future workshops" to assess attendee feedback.

After collecting the data, the feedback was analyzed by 2 separate researchers. These researchers used the conceptual analysis method to assess all the responses and develop themes inductively. The researchers gave their separate viewpoints on themes that could be developed among the responses. The themes that emerged were then analyzed by a third researcher who compiled and developed the final themes.

\section{Description of the Sessions}

The following were the sessions covered in the workshop:

\section{Pharmacy Services at NCHRC}

This first session mainly highlighted the structure, services, and functioning of the pharmacy at NCHRC. The speaker informed about the staffing system of the pharmacy and its division into in-patient pharmacy, out-patient pharmacy and pharmacy store. The speaker also highlighted the features of the pharmacy including bedside dispensing, credit billing and practice of clinical pharmacy, stressing on the significance of continuous teamwork among pharmacists, doctors and nurses for a proper prescription, dispensing and administration of medication.

\section{Regional Pharmacovigilance Center at NCHRC: Where are We?}

The resource person in this session provided insight into the history of the PV system in Nepal and the establishment of NCHRC as the 12th regional PV center and the 1 st oncology-based center to initiate adverse drug reaction reporting in Nepal. The speaker elaborated on the activities that were being conducted at the hospital related to PV and ADR reporting. The speaker also focused on the research activities being carried out in Nepal related to PV and adverse drug reactions. Furthermore the speaker expanded the role of education and intervention by clinical pharmacists in improving the knowledge, attitude and practice of healthcare workers towards PV and the need to carry out more research into this field. The speaker also highlighted the importance of PV in oncology-based hospitals in Nepal.

\section{Adverse Drug Reactions and Pharmacovigilance}

In this session, the speaker described the concept of ADR and its various types. This was followed by the discussion on the WHO-UMC and the Naranjo scales used to conduct causality assessment between the reaction and the drug. Besides, the 
speaker also focused on the importance of PV in patient safety, generation of knowledge about ADRs, especially delayed ADRs and reduction of costs, hospital stay and mortality. The attribution of an adverse reaction to a particular drug depends on time relation, exclusion of other events (drug or chemical), previous knowledge about the ADR, de-challenge and re-challenge phenomena, all of which are taken into account in the World Health Organization-Uppsala Monitoring Center (WHO-UMC) scale. The causality is classified as one of the following: certain, probable, possible, unlikely, conditional and unclassifiable. ${ }^{3}$ The Naranjo scale is a tool comprising weighted questions, each with a definite score that determines the causality as $0-$ doubtful, 1 to $4-$

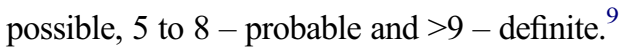

The system of ADR surveillance comprises of the national PV centers that collect, collate and evaluate reports of ADRs from regional centers and forward the reports to the WHO database called the VigiBase at the WHO Collaborating Center for International Drug Monitoring, Uppsala, Sweden. ${ }^{10,11}$ The significance of $\mathrm{PV}$ is to prevent or reduce the hazards to the patients from the use of medication. Clinical trials of new medication often do not cover the safety issues of the drug, for which post-marketing surveillance of drugs becomes crucial. $^{12}$

At the end of the session, the resource person introduced the topics of haemovigilance and materiovigilance as extensions of PV.

Pharmacovigilance in Nepal and Its Implementation at a Cancer Hospital

In this session, the speaker elaborated about the history of PV in Nepal, beginning with the Department of Drug Administration (DDA) in October 2004 and the establishment of various regional PV centers that report to the DDA via a national ADR reporting form. The speaker also highlighted the current scenario of under-reporting of ADRs in Nepal and strategies regarding the implementation of pharmacovigilance in a cancer hospital.

\section{Alternative Medicine and Complementary (CAM) Health Approach in Cancer}

This session primarily focuses on the concept of CAM, their practice and focused on certain herbs, the advantages of which have been scientifically proven. The speaker highlighted the various CAM components such as dietary supplements, manipulative practices, mind-body systems, energy medicine, and ancient medical systems such as Ayurveda. The speaker explained the uses of CAM, the benefits of certain practices and integration of CAM into conventional treatment plans along with the beneficial and adverse effects of herbal supplements.

\section{Hands-on Training}

In this session, the speaker introduced two sample cases of ADRs. The audience members were then oriented to carry out causality assessment. In the first case, the WHO-UMC scale was used for establishing causality while in the second case, the Naranjo scale was employed. After the adverse events had been empirically attributed to the use of the drugs using the causality assessment tools, the participants were trained to use the national ADR reporting form developed by the DDA (National Pharmacovigilance Center). The speaker elucidated the details of the ADR reportingform. The trainer then demonstrated the method of data entry into the Vigiflow system of the WHO-UMC.

\section{Statistical Analysis}

Descriptive analysis was performed to assess the feedback of the workshop, its best feature, potential drawbacks and areas for improvement (Appendix S1). The qualitative data were converted to quantitative data via the creation of themes and thus, were presented as responses to the feedback questions. Similarly, the data on age-groups of the participants, the response rate and professional background were presented in terms of frequency and proportion. The data from the feedback forms were entered in MS-Excel 2010 (Microsoft Corporation, Redmond, WA, USA) and analysis was performed.

\section{Major Quantitative Analysis Results}

Seventy-five participants attended the workshop, out of which only 64 completely filled up the forms (response rate $85.33 \%$ ). $68.7 \%$ (44) of the participants were female, while the rest $(31.3 \%, 20)$ were males. The age distribution of the participants was as follows: $21.9 \%(14), 50 \%(32)$, $15.6 \%$ (10) and $12.5 \%$ (8) in the 20-25, 26-30, 31-35 and 36-40 years category, respectively. Among the participants, $21.9 \%$ (14) were doctors, 39.1\% (25) were nurses, and $29.6 \%$ (19) were pharmacists while the rest 9.4\% (6) belonged to other professional categories. The highest number of participants were from the fields of Pharmacy, Clinical Pharmacy and Clinical Pharmacology (32.8\%), followed by Surgical Oncology (15.6\%) (Appendix S2).

\section{Major Qualitative Analysis Results}

The Best Feature of the Workshop

The most impressive features of the workshop, as described 
by the participants, can be grouped into 3 themes, which are practical demonstration and hands-on training with comments such as "filling up of Naranjo-Scale and WHO UMC forms", "practical aspect, ADR form filling and reporting" and "test and hands-on training"; broad topic coverage with comments such as "needful topic, knowledge about ADR and Vigiflow", "all topics covered briefly, as needed for daily reporting" and "knowledge about ADR \& pharmacovigilance"; and good resource persons with feedback such as "resource person's presentation", "well explained" and "topics were clear".

\section{Dissatisfaction About the Workshop}

The dissatisfaction expressed by the participants could be pooled into two primary themes, which are lack of interaction during the lecture sessions with comments such as "less interaction", "no interaction" and "monotonous" and lack of proper time management with feedback such as "short of time", "time limit" and "time-limited".

Recommendations for Improving Forthcoming Workshops The recommendations could be summed up into three primary themes including conducting more workshops such as this one in the future with comments such as "detailed class needed for training on ADR reporting, vigiflow and causality assessment", "more hands-on training" and "internal exposure to pharmacovigilance and different types of signal detection"; use of visual aids with suggestions such as "visual aids including video", "more pictures and presentations" and more interactive sessions with feedback such as "more interactive sessions", "group discussion and presentation" and "round table discussion is more useful than lecture".

\section{Discussion}

The significance of pharmacovigilance is well pronounced and it is especially relevant in the case of lower and middle-income countries such as Nepal, where the incidence of reporting of ADRs, as elucidated by the speakers of this program, is very low. ${ }^{13}$ Hence, it is paramount to conduct similar programs to enhance the knowledge of ADRs among healthcare workers involved in prescribing, dispensing and administering drugs. NCHRC established the first regional pharmacovigilance center in a cancer hospital Nepal and also initiated events such as focusing to strengthen pharmacovigilance. ${ }^{14-16}$ The current program aimed at disseminating knowledge about pharmacovigilance and reporting of ADRs.
The participants were from a multitude of professions with a predominance of nurses. The number of female participants was higher than males since the nurse population comprises solely of females. In terms of disciplines, the fields with the highest number of participants was pharmacy. Pharmacists are among primary pillars of drug use $^{17,18}$ and thus, their active participation was anticipated.

The collection of feedback is essential for the improvement of the content of any educational material. ${ }^{19,20}$ The current study focuses on the collection, analysis, and interpretation of the feedback collected post-workshop. ${ }^{21}$

The various topics that were presented by the panel of speakers succeeded in generating knowledge about ADRs and pharmacovigilance among the participants as is shown from the post-event feedback. The significance of this workshop can be inferred from the fact that many of the participants regarded the knowledge, which was disseminated to be the best feature of the event. Also, hands-on training has proven to be another important feature of this workshop. It has been demonstrated that lack of knowledge about the reporting procedure and the existence of a national pharmacovigilance system are hurdles in ADR reporting. ${ }^{22}$ Based on the feedback, the handson training and the information about Vigiflow in the current workshop helped in addressing such issues.

It is interesting to note that the participants requested for a more interactive session in later events. The practice of using lectures solely would not be as productive as other means of teaching. ${ }^{23}$ Interaction, in the form of a dialogue between the instructor and the participant, should be implemented ${ }^{8}$ to improve learning outcomes; however, the size of the class is a major factor in deciding the extent of interaction. ${ }^{24}$ Likewise, use of visual aids such as pictures and diagrams has been another recommendation by the participants. Such use has been shown to help in grouping novel concepts and retention of such concepts in memory. ${ }^{25}$

The participants recommended that educational events such as this could be carried out more frequently. The practice of reporting ADRs to regional pharmacovigilance centers and system of pharmacovigilance is in their infancy in Nepal, ${ }^{4}$ coupled with poor awareness about ADR reporting, ${ }^{26}$ Thus, the authors shared the opinion of the participants regarding the necessity of similar programs in the future. This thought is has been shown by several findings that hold testament to the improvement in ADR reporting through educational interventions. ${ }^{5-8,23}$ Conducting this kind of workshop would be helpful for all the stakeholders during drug use to report ADRs and enhance the culture of reporting ADRs. $^{27}$ 


\section{Limitations}

The sample size in our study was only 64 . The workshop was carried out in a super-specialized cancer care center, which might not be representative of other healthcare facilities in Nepal. Representativeness analysis has not been carried out. Moreover, the effectiveness of the workshop has not been evaluated in this study in terms of lasting changes in behavior, knowledge or attitude.

\section{Conclusion}

Workshop on adverse drug reaction reporting, pharmacovigilance and its implementation in cancer Hospital was successfully organized in NCHRC. The feedback suggests that future workshops of similar nature should be more interactive in nature, irrespective of time constraints. The increase in participant awareness and interest in this field is indicated by the recommendation to conduct future in-depth workshops focusing on these topics.

\section{Ethical Approval}

The approval for conducting workshop was taken from Nepal Cancer Hospital and Research Center, Harisiddhi, Lalitpur, Nepal. Ethical clearance for conducting workshop is not required from the institutional review committee (IRC).

\section{Acknowledgments}

The authors acknowledge Mr. Santosh KC, Senior Drug Administrator, Department of Drug Administration and Dr. Amit Shrestha, Consultant Hematologist, Nepal Cancer Hospital and Research Center (NCHRC) for chairing the session during the workshop session. The authors also acknowledges Dr. Sudip Shrestha, Executive Chairman and Senior Consultant Medical Oncologist of NCHRC, organizing committee of the workshop, Siba Life Sciences and all the participants of the workshop for their active participation.

\section{Disclosure}

The authors report no conflicts of interest in this work.

\section{References}

1. World Health Organization. International Drug Monitoring: The Role of National Centres, Report of a WHO Meeting [Held in Geneva from 20 to 25 September 1971]. World Health Organization; 1972.

2. World Health Organization. WHO Operational Package for Assessing, Monitoring and Evaluating Country Pharmaceutical Situations: Guide for Coordinators and Data Collectors. Geneva: World Health Organization; 2007.
3. The Uppsala Monitoring Centre. The use of the WHO-UMC system for standardised case causality assessment. Available from: https:// www.who.int/medicines/areas/quality_safety/safety_efficacy/ WHOcausality_assessment.pdf. Accessed July 24, 2019.

4. Santosh KC, Tragulpiankit P, Gorsanan S, Edwards IR. Attitudes among healthcare professionals to the reporting of adverse drug reactions in Nepal. BMC Pharmacol Toxicol. 2013;14:16. doi:10. 1186/2050-6511-14-16

5. Figueiras A, Herdeiro MT, Polonia J, Gestal-Otero JJ. An educational intervention to improve physician reporting of adverse drug reactions: a cluster-randomized controlled trial. JAMA. 2006;296 (9):1086-1093. doi:10.1001/jama.296.9.1086

6. Bracchi RC, Houghton J, Woods FJ, Thomas S, Smail SA, Routledge PA. A distance-learning programme in pharmacovigilance linked to educational credits is associated with improved reporting of suspected adverse drug reactions via the UK yellow card scheme. $\mathrm{Br}$ $J$ Clin Pharmacol. 2005;60(2):221-223. doi:10.1111/j.1365-2125. 2005.02419.x

7. Tabali M, Jeschke E, Bockelbrink A, et al. Educational intervention to improve physician reporting of adverse drug reactions (ADRs) in a primary care setting in complementary and alternative medicine. BMC Public Health. 2009;9:274. doi:10.1186/1471-2458-9-274

8. Herdeiro MT, Ribeiro-Vaz I, Ferreira M, Polonia J, Falcao A, Figueiras A. Workshop- and telephone-based interventions to improve adverse drug reaction reporting: a cluster-randomized trial in Portugal. Drug Saf. 2012;35(8):655-665. doi:10.1007/BF03261962

9. Naranjo CA, Busto U, Sellers EM, et al. A method for estimating the probability of adverse drug reactions. Clin Pharmacol Ther. 1981;30 (2):239-245. doi:10.1038/clpt.1981.154

10. Lindquist M. VigiBase, the WHO global ICSR database system: basic facts. Drug Inf J. 2008;42(5):409-419. doi:10.1177/0092 86150804200501

11. Olsson S. The role of the WHO programme on International Drug Monitoring in coordinating worldwide drug safety efforts. Drug Saf. 1998;19(1):1-10. doi:10.2165/00002018-199819010-00001

12. Najafi S. Importance of pharmacovigilance and the role of healthcare professionals. J Pharmacovigil. 2018;6:252.

13. Karki KBA, Kumar K, Gyawali P, et al. Quality of Drugs and Drug Use Patterns at Different Level of Health Care Settings in Nepal, 2016. Kathmandu, Nepal.: Nepal Health Research Council; 2017.

14. Shrestha S, Shrestha S, Khanal S. Establishment of the first cancer hospital-based pharmacovigilance center in Nepal. Res Social Adm Pharm. 2018;14(11):1088-1089. doi:10.1016/j.sapharm.2018.07.017

15. Sharma S, Khanal T, Shrestha S, Adhikari B. A celebration of World Pharmacist Day 2018 focusing to strengthen the pharmacy services at an oncology-based hospital in Nepal: inspiration for others in developing countries. Res Social Adm Pharm. 2019;15(1):117-118. doi:10.1016/j.sapharm.2018.09.022

16. Ghimire BR, Shrestha S, Adhikari B, Shrestha S. Establishment and achievements of drug and therapeutic committee at the oncology-based hospital of Nepal. Indian J Pharm Pract. 2019;12 (1):41-44. doi:10.5530/ijopp.12.1.8

17. Shrestha S, Shrestha S, Palaian S. Can clinical pharmacists bridge a gap between medical oncologists and patients in resource-limited oncology settings? An experience in Nepal. J Oncol Pharm Pract. 2019;25(3):765-768. doi:10.1177/1078155218784734

18. Ghayur MN. Pharmacy education in developing countries: need for a change. Am J Pharm Educ. 2008;72(4):94.

19. Keane E, Labhrainn I. Obtaining student feedback on teaching \& course quality. Brie Ing Paper. 2005;2:1-19.

20. Shrestha S, Danekhu K, Sharma N, et al. Workshop on proposal writing on research for health care professionals: a brief report. $J$ Multidiscip Healthc. 2019;12:565-572. doi:10.2147/JMDH.S211257

21. Fry H, Ketteridge S, Marshall S. A Handbook for Teaching and Learning in Higher Education: Enhancing Academic Practice. Routledge; 2008. 
22. Palaian S, Ibrahim MI, Mishra P. Health professionals' knowledge, attitude and practices towards pharmacovigilance in Nepal. Pharm Pract (Granada). 2011;9(4):228. doi:10.4321/S1886-36552011000400 008

23. Hartman J, Harmark L, van Puijenbroek E. A global view of undergraduate education in pharmacovigilance. Eur J Clin Pharmacol. 2017;73(7):891-899. doi:10.1007/s00228-017-2237-z

24. McCroskey JC, JF Andersen. The relationship between communication apprehension and academic achievement among college students. Hum Commun Res. 1976;3(1):73-81. doi:10.1111/j.14682958.1976.tb00506.x
25. Alesandrini KL. Pictures and adult learning. Instructional Sci. 1984;13(1):63-77. doi:10.1007/BF00051841

26. Jha N, Rathore DS, Shankar PR, Gyawali S. Pharmacovigilance knowledge among patients at a teaching hospital in Lalitpur District, Nepal. J Clin Diagn Res. 2014;8(3):32-34. doi:10.7860/ JCDR/2014/7378.4097

27. Suyagh M, Farah D, Abu Farha R. Pharmacist's knowledge, practice and attitudes toward pharmacovigilance and adverse drug reactions reporting process. Saudi Pharm J. 2015;23(2):147-153. doi:10.1016/ j.jsps.2014.07.001

\section{Publish your work in this journal}

Advances in Medical Education and Practice is an international, peerreviewed, open access journal that aims to present and publish research on Medical Education covering medical, dental, nursing and allied health care professional education. The journal covers undergraduate education, postgraduate training and continuing medical education including emerging trends and innovative models linking education, research, and health care services. The manuscript management system is completely online and includes a very quick and fair peer-review system. Visit http://www.dovepress.com/testimonials.php to read real quotes from published authors. 